JURNAL PENJAMINAN MUTU

LEMBAGA PENJAMINAN MUTU

INSTITUT HINDU DHARMA NEGERI

DENPASAR

\title{
INOVASI PENINGKATAN MUTU PEMBELAJARAN AGAMA HINDU YANG KONTEKSTUAL
}

\author{
Oleh \\ I Nyoman Kiriana \\ Institut Hindu Dharma Negeri Denpasar \\ kiriana@ihdn.ac.id
}

Diterima 4 November 2017, direvisi 6 Januari 2018, diterbitkan 28 Pebruari 2018

\begin{abstract}
Religious learning in the era of technology and information will experience many obstacles in the realization if not accompanied by a contextual learning model. Teachings delivered will be more successful if delivered by forming aspects of sense and aspect ratio that can be accepted with common sense. Thus in the learning of religion should make the maximum innovation adjusted with space and time and in tune with the changes and development of the era. Utilization of information technology is very important in the learning of Hinduism for learning purposes can be achieved in accordance with expectations
\end{abstract}

\section{Kata Kunci: Innovation, Learning, Hindu And Contextual}

\section{PENDAHULUAN}

Agama merupakan wahyu yang diturunkan Tuhan untuk manusia. Fungsi dasar agama adalah memberikan orientasi, motivasi dan membantu manusia untuk mengenal dan menghayati sesuatu yang sakral. Lewat pengalaman beragama (religious experience) manusia memiliki kesanggupan, kemampuan dan kepekaan rasa untuk mengenal dan memahami eksistensi Sang Ilahi (Syafe'i dalam Maman dkk, 2006 : 1).

Secara teoretis agama merupakan sistem yang memiliki daya bentuk dalam membangun ikatan sosial religius masyarakat. Bahkan agama mampu membentuk katagori sosial yang terorganisasi sedemikian rupa dan menjadi landasan dogma dan tata nilai dalam masyarakat. Dengan demikian agama memiliki daya konstruktif, regulatif dan formatif untuk membangun tatanan hidup terutama dalam masyarakat dimana nilai dan norma itu diterima dan diakui keberadaannya.

Agama menduduki posisi sentral pada periode klasik yang bersifat kosmosentris sampai periode pertengahan bersifat teosentris. Pada periode modern dimana manusia sebagai pusat kajian (antroposentris) muncul keraguan akan peranan agama dalam kehidupan masyarakat. Lebih-lebih pada periode posmodernisme. Karl Marx misalnya menganggap agama sebagai candu masyarakat yang dapat memabukkan karena agama 
memberikan kebahagiaan yang semu sehingga masyarakat terlena. Nietzsche lebih ekstrim menyatakan 'Tuhan telah mati' serta Stackhouse menyatakan 'bisakah Tuhan dipercaya ?' Jika benar Tuhan ada dan Maha Kuasa, Maha Pengasih, mengapa begitu banyak kejahatan di dunia ini? Itu merupakan bukti bahwa peranan agama dalam membangun citra masa ini belum berhasil secara maksimal.

Dengan demikian agama memiliki sifat embivalen yaitu di satu sisi agama mengajarkan perdamaian dan kasih sayang terhadap semua mahluk, di sisi lain agama justru dianggap sebagai sumber perpecahan dan kerusuhan. Agama yang awalnya menuntun manusia untuk bersikap baik dan berbudi pekerti yang luhur, justru membuat suasana semakin keruh yang disebabkan oleh sikap fanatisme. Akibatnya ada suatu kesenjangan antara teks dan konteks.

Keterpurukan peranan agama juga merambah pada sistem pengajaran agama. Tak terkecuali pada pengajaran agama Hindu. Hal ini terbukti semakin minimnya minat masyarakat untuk studi di sekolah atau perguruan tinggi yang bernuansa agama Hindu. Perguruan tinggi yang bernuansa agama menjadi "sisan pilih". Ada kesan umum yang berkembang dalam masyarakat akademis bahwa belajar agama Hindu itu : membosankan, monoton, kurang berguna, akan menjadi pamangku, tidak relevan untuk mencari kerja dan marginal serta berbagai stereotipe lain yang cenderung negatif. Untuk mengantisipasi hal itu diperlukan inovasi yang kontekstual dalam sistem pembelajaran agama Hindu sehingga masyarakat akan lebih tertarik untuk mempelajari agama Hindu.

\section{PEMBAHASAN}

\subsection{Agama Hindu di Bali}

Agama Hindu hendaknya dipahami secara utuh dan menyeluruh. Dengan pemahaman yang menyeluruh akan didapatkan peta dari ajaran agama Hindu tersebut. Sebagai halnya orang akan tahu tentang dunia karena jasa dari globe atau peta. Walaupun orang tidak pernah ke tampat yang ditunjuk oleh peta atau globe tersebut. Setidaknya ia telah mendapat gambaran tentang keadaan dunia melalui globe. Demikian pula pemahaman tentang ajaran agama Hindu. Ada beberapa peta yang dilakukan untuk memahami ajaran agama Hindu yaitu: peta literatur, peta historis, peta struktur ajaran, dan peta dinamika kehidupan.

Dari pendekatan sejarah dapat diketahui bahwa agama Hindu adalah agama terbuka artinya agama yang menerima paham dari berbagai kalangan secara adaptif. Agama Hindu tidak menutup diri sebagai agama yang terpaku kaku pada apa yang tercantum dalam teks kitab suci, sane kamargiang boya ja kecaping sastra, nanging daging sastra. Agama Hindu juga adalah agama berkelanjutan (sanatana dharma). Ia tidak berhenti pada satu titik. Ia senantiasa berevolusi sehingga melahirkan bentuk-bentuk yang bervariasi tetapi azasnya tetap sama. Misalnya ajaran yang terkandung dalam Weda berlanjut pada ajaran Upanisad yang memandang Yang Maha Kuasa adalah Brahman yang melahirkan ajaran Wedanta. Ajaran Wedanta melanjut ke dalam ajaran Purana yang mengajarkan paham Brahma, Wisnu dan Siwa. Dari ajaran Purana berlanjut pada ajaran Tantra pemuja Sakti yang menyertai paham Brahma, Wisnu dan Siwa. Pada saat sekarang ajaran-ajaran tersebut terus berkembang menjadi paham-paham lain yang banyak jumlahnya. Jadi Agama Hindu di Bali adalah agama Hindu yang disarikan dari berbagai-bagai sumber dan paham yang mempunyai ajaran dan bentuk tersendiri yang berbeda dengan lainnya, akan tetapi esensinya secara substansi adalah sama.

Dari pendekatan kepustakaan menunjukkan bahwa setelah Kitab Weda diturunkan kepustakaan Hindu terus berlanjut. Dari Weda muncul buku-buku Brahmana dan melanjut menjadi Aranyaka, Upanisad, Dharmasastra, Itihasa, Purana, Darsana, Tantra dan kemudian disarikan di Jawa dan di 
Bali dalam bentuk-bentuk lontar. Lontarlontar inilah menjadi dasar pelaksanaan agama Hindu di Bali.

Dari pendekatan struktur ajaran dapat dilihat dalam Weda. Weda mengajarkan Tuhan itu Esa adanya. Walau banyak dewa-dewa yang diserukan dalam Weda, namun dewa-dewa itu hanyalah aspek dari Ia Yang Esa. Dikatakan Yang Esa dalam yang banyak, yang banyak dalam Yang Esa (ekatva anekatva swalaksana bhatara). Bila Agni dewa tertinggi, maka semua dewa adalah Agni Ajaran yang demikian berlanjut dalam Upanisad. Bahkan dalam Upanisad, Brahman disamakan dengan semua yang ada ini (sarva khalu idam Brahman). Demikian pula dalam Narayana Upanisad (di Bali disebut Catur Weda Sirah), Narayana disamakan pula dengan semua yang ada ini (Narayana evedam sarvam). Agama Hindu di Bali memuja Sang Hyang Widhi sebagai Bhatara Siwa, jadi Bhatara Siwalah semua bhatara-bhatara, demikian juga bhutakala itu. Hal ini digambarkan Bhatara Siwa yang Esa menjadi delapan dewata dalam pangider-ider.

Dimanapun agama Hindu dianut, budaya lokal menjadi media pendukung pelaksanaan ajarannya. Agama Hindu tidak memaksakan suatu budaya tertentu. Dengan demikian antara agama, tradisi, kepercayaan lokal, seni, pola hidup dan sebagainya serasi dengan apa yang diyakini. Karena budaya berbeda-beda maka tampaklah bentuk-bentuk tata pelaksanaan hidup beragama Hindu bervariasi pula.

Di samping itu yang menjadi dasar hidup beragama yang amat penting diperhatikan adalah dinamika kehidupan. Dimanapun manusia hidup tidak pernah berada dalam keadanaan statis, hidup terus berdinamika, bergerak maju dan berubah. Apa yang dikatakan baik dahulu, sekarang kadangkadang tidak baik lagi. Kehidupan terus bergulir dan berubah. Manusia hendaknya juga mengikuti perubahan tersebut. Bila ia tidak ikut berubah maka ia akan ditinggalkan dan tenggelam dilindas oleh perubahan. Karena itu harus selalu ada upaya merumuskan dan menginterpretasi agama Hindu di Bali ke depan sehingga dapat mengantarkan umatnya berenang dalam perubahan dengan pendekatan yang humanis dan keteladanan. Usaha yang amat penting adalah adanya inovasi pembelajaran agama Hindu yang kontekstual sehingga agama Hindu dalam realisasinya akan berkelanjutan (sanatana dharma).

\subsection{Inovasi Pembelajaran (Enjoy Learning) dalam Penggunaan Teknologi Informasi (IT)}

Bertitik tolak dari kesan umum pada pelajaran agama Hindu yang membosankan, monoton, kurang berguna, akan menjadi pamangku, tidak relevan untuk mencari kerja dan marginal, maka menurut hemat saya, dalam proses pengajaran agama Hindu diperlukan inovasi dengan memanfaatkan teknologi dan informasi (IT). Pemakaian IT ini adalah untuk merevitalisasi (penyegaran kembali) dari sistem pengajaran sebelumnya yang mungkin harus disesuaikan dengan perkembangan jaman. Hal ini disebabkan karena masyarakat akademis sekarang ini menginginkan sesuatu yang bersifat instan (cepat saji). Masyarakat sekarang sudah melek teknologi dan informasi. Sebagai bukti siswa SD kelas III sudah mahir menggunakan handphone, bahkan sudah mahir mengakses internet danfacebook. Dengan adanya kemajuan tersebut para guru atau pengajar akan lebih mudah mengaplikasikan pelajaran yang diajarkan. Jangan sampai para pengajar belum mampu menggunakan teknologi dan informasi secara maksimal pada era sekarang ini.

Dengan menggunakan IT diharapkan minat siswa untuk belajar agama Hindu akan semakin meningkat. Karena ada inovasi dalam pembelajaran agama Hindu. Demikian pula kompetensi pelajaran akan menjadi lebih realistis. Di samping itu bahan pelajaran akan terkesan lebih menarik dan aktual karena relevan dengan perkembangan zaman. 
Pada sistem pengajaran sebelumnya para guru menggunakan metode pembelajaran dengan sistem kuliah mimbar, dimana para guru yang aktif sedangkan siswa bersikap pasif. Dengan menggunakan IT diharapkan metode pembelajaran lebih mengarahkan pada aplikasi dan berorientasi pembelajaran bukan pengajaran. Para guru dituntut untuk berinovasi sehingga siswa menjadi kreatif.

Demikian pula sarana pembelajaran tidak lagi menggunakan konsep klasik (dikte) dengan menancapkan atau menulis huruf-huruf di papan tulis (whiteboard), namun perlu ditambah dengan menggunakan IT misalnya : in-focus, LCD dan lain-lain. Para guru membuat bahan pembelajaran dengan menggunakan Microsoft Office Power Point atau pemutaran film documenter, mencari bahan-bahan agama Hindu yang up to date. Dengan demikian, siswa akan lebih tertarik untuk mengikuti proses pembelajaran. Di samping itu materi pembelajaran lebih didekatkan pada hal-hal yang bersifat aktual dan integrasi antar desiplin ilmu serta memanfaatkan secara optimal IT dan komunikasi.

\subsection{Inovasi Pembelajaran (Enjoy Learning) dalam Memahami ajaran Agama Hindu yang Kontekstual}

Walaupun tidak ada sumber sastra menyebutkan, dalam kenyataannya ajaran agama Hindu di Bali dapat dipilah menjadi tiga kerangka : tattwa, susila dan upakara. Ketiga bagian ini merupakan satu kesatuan yang tak terpisahkan. Seseorang yang pandai dalam tattwa, namun tidak bersusila belum dapat dikatakan pemeluk agama Hindu yang baik. Seseorang yang tingkah lakunya baik namun tidak pernah sembahyang, tidak pernah mempersembahkan upakara juga belum dapat dikatakan sebagai seorang pemeluk agama Hindu yang baik. Demikian seterusnya. Ketiga bagian itu saling melengkapi satu dengan yang lain dan dilaksanakan dalam perimbangan yang berbeda. Ajaran tattwa diimplementasikan melalui konsep panca sraddha (Brahman, atman, karmaphala, punarbhawa dan moksa). Ajaran susila dituangkan melalui konsep ajaran trikayaparisuddha (kayika, wacika dan manacika) sedangkan upakara dijabarkan melalui konsep panca yajna (dewa yajna, pitra yajna, rsi yajna, manusa yajna dan bhuta yajna).

Budi pekerti dalam ajaran agama Hindu merupakan implementasi dari ajaran susila. Budi pekerti adalah suatu realitas normatif yang tekstual dengan keniscayaan-keniscayaannya yang normologik di dunia sollen, sedangkan perilaku adalah suatu realitas emperik yang tidak lagi tekstual melainkan kontekstual dengan keniscayaan-keniscayaannya yang normologik di dunia sein. Tak selamanya apa yang normatif itu akan dapat dengan mudah ditransformasikan menjadi kenyataan-kenyataan normologik yang tetap utuh, tanpa terdistorsi dan terekonstruksi oleh konteks-konteksnya.

Andaikata orang mengatur dirinya bertingkah laku hanya karena orang lain, maka sewaktu-waktu ia akan berani saja berbuat tidak baik, jika tidak ada orang yang melihatnya, karenanya tidak ada orang yang memberikan hukuman. Namun orang sadar bahwa di samping orang lain dan alam, maka Hyang Widhi-lah yang akan menentukan akibat dari perbuatannya. Kalau perbuatannya baik maka baik pula akibatnya dan sebaliknya. Kalau orang berani mengiris kulitnya, alam akan memberikan hukumannya. Orang itu akan luka dan sakit. Tidak ada seorang pun yang luput dari hukuman alam. Dengan menyadari adanya hukum alam itu orang akan mengatur dirinya dalam berbuat sesuatu sesuai dengan hukum alam itu agar hidupnya selamat. Tetapi bagaimanakah halnya dengan perbuatanperbuatan jahat seperti mencuri, menyiksa, menipu dan sebagainya. Yang tampaknya tidak membawa akibat apa-apa bila tak ada orang lain melihatnya ? Dirinya sendiri adalah menjadi saksi. Seorang tak dapat mengingkari akan segala sesuatu perbuatannya terhadap dirinya 
sendiri, karena di dalam dirinya ada sesuatu yang tak dapat ditipu dan dibohongi yaitu Sanghyang Atma.

Atman ialah bagian dari Sanghyang Widhi berada di mana-mana. Beliau mengetahui segala. Karena itu orang tak dapat menyembunyikan segala perbuatannya terhadap beliau. Atman adalah saksi agung akan segala kejadian di alam semesta ini. Ia akan menentukan akibat perbuatan seseorang. Hal ini dijelaskan dalam Adi Parwa sebagai berikut:

Adityacandrâw anilânalan ca dyaur bhùmir âpo hådayam yamaúca, Ahaúca râtriúca ubhe ca sandhye darmmaúca jânâti narasya wåttam.

Aditya Sanghyang Sùrya, Candra, Sanghyang Wulan, Anilânala Sanghyang Hangin mwang apuy. Tumùt ta Sang Hyang Àkâsa Påthiwî mwang Toya, mwah Sanghyang Atma, Sanghyang Yama, tamolah ing rât kabeh. Nâhan tang rahina wëngi mwang sandhyâ, lâwan Sanghyang Dharmma sira, sang dewata mangkana tiga wëlas kweh nira, sira ta mangawruhi ulahning wwang ring jagat kabeh, tan këna byapara nireng rât. (Adi Parwa, X.37)

Matahari, bulan, angin dan api. Juga ikut angkasa, bumi dan air, serta Hyang Atma, Hyang Yama, yang diam di seluruh dunia. Demikian pula siang, malam dan senja kala dengan Hyang Dharma. Para dewa itu dengan demikian - tiga belas banyaknya. Semua itu tahu akan tingkah laku orang di seluruh dunia. Tidak dapat dikelabui. Dewa itu memenuhi dunia. (Widyatmanta, 1958 : 97).
Bagai sebuah bangunan yang kuat perlulah didirikan di atas dasar yang kuat, demikian pula halnya dengan budi pekerti harus didirikan di atas fondasi yang kuat. Dasar yang kuat itu adalah ajaran-ajaran agama Hindu.

Dalam melakukan inovasi pembelajaran agama Hindu yang kontekstual, sangat diperlukan untuk selalu melakukan adaftasi pengetahuan agama Hindu agar sesuai dengan ruang dan waktu kekinian. Seperti misalnya dalam perkembangan pemahaman terhadap pengertian agama yang dulu sering diartikan sebagai tidak pergi, sehingga sekarang sudah semakin jelas bahwa pengertian âgama itu adalah datang mendekat yang dimaksud adalah ajaran yang disampaikan oleh guru datang mendekati murid-muridnya sehingga terus berkembang sampai munculnya ajaran upanisad. Demikian pula seterusnya pengertian Sanatana Dharma (dharma yang berkelanjutan), Weda (pengetahuan suci), Rwa Bhineda (dibedakan dua), Tattva (olah bathin), Filsafat (olah pikir), Tat Tvam Asi (itu adalah engkau), Drati Krama (melarikan gadis), Yadnya (pengorbanan) dan sebagainya.

\section{SIMPULAN}

Proses pengajaran agama Hindu hendaknya mengikuti perkembangan zaman dengan mengoptimalkan penggunaan teknologi dan informasi. Dengan itu diharapkan siswa akan menjadi lebih kreaktif serta guru-guru selalu berusaha untuk berinovasi. Inovasi ini bertujuan agar pembelajaran agama Hindu akan menjadi lebih menarik dan menyenangkan, bersifat realistis, dapat menjadi motivator serta membantu siswa untuk mengembangkan potensi yang ada dalam dirinya secara maksimal terutama yang menyangkut tentang hal-hal yang bersifat spiritual. Dengan demikian agama tidak saja pencarian ke luar dirinya, akan tetapi lebih merealisasikan pencarian ke dalam untuk menemukan yang ada di dalam. 


\section{DAFTAR PUSTAKA}

Herawan, K. D., \& Sudarsana, I. K. (2017).

Relevansi Nilai Pendidikan Karakter

Dalam Geguritan Suddhamala Untuk Meningkatkan Mutu Pendidikan Di Indonesia. Jurnal Penjaminan Mutu, 3(2), 223-236.

Kadjeng, I Nyoman dkk..1996/1997.

Sarasamuccaya. Denpasar: Pemerintah Daerah Tingkat I Bali.

Kiriana, I. N. (2016). SINKRETISME

DALAM AGAMA HINDU DAN BUDDHA DI BALI. Jurnal Penjaminan Mutu, 1(2), 71-78.

Mantra, Ida Bagus.1993. Tata Susila Hindu Dharma. Jakarta : Hanoman Sakti.

Maman.U.dkk. 2006. Metodologi Penelitian Agama. Jakarta : Raja Grafindo Persada.

Oka, I Gusti Agung.1994. Slokantara. Jakarta : Hanoman Sakti.
PGAHN 6 Tahun Singaraja.1982-1983. Niti Sastra. Denpasar : Parisada Hindu Dharma Pusat.

Sura, I Gede.1977. Sekitar Peraturan Tingkah Laku. Denpasar : stensilan.

Sura, I Gede. 1985. Pengendalian Diri dan Etika Dalam Ajaran Agama Hindu. Jakarta: Dirjen Bimas Hindu-Budha.

Sura, I Gede dkk.1994. Agama Hindu Sebuah Pengantar. Denpasar: Kayumas Agung.

Stackhouse, John G. JR. 2008. Bisakah Tuhan Dipercaya ?. Jakarta : Gramedia.

Titib, I Made. 2003. Menumbuhkembangkan Pendidikan Budi Pekerti Pada Anak Perspektif Agama Hindu. Jakarta : Parisada Hindu Dharma Indonesia Pusat.

Widyatmanta, Siman.1958. Adiparwa I. Yogyakarta : Toko Buku "Spring". 